\title{
The evidence for glutamine use in the critically-ill
}

\author{
Richard D. Griffiths \\ Intensive Care Research Group, Department of Medicine, Duncan Building, UCD, Daulby Street, \\ University of Liverpool, Liverpool L69 3GA, UK
}

\begin{abstract}
Research into the metabolic role of glutamine in trauma and sepsis brings evidence to suggest a conditional deficiency occurs because increased and altered tissue demands exceed endogenous production. Such a deficiency has functional implications, and the restorative provision of parenteral glutamine has been shown to offer improved clinical outcomes in a variety of conditions. In the critically-ill it is associated with improvements in immune function, and improved survival from infection leading to an overall improved outcome.
\end{abstract}

Glutamine: Critical illness: Immune function: Parenteral glutamine: Intensive care

The year 2000 was the centenary of the birth of Sir Hans Krebs who established the metabolic foundation for our understanding of glutamine (Krebs, 1935). He established the pivotal relationship between glutamine and glutamate, and the important position that glutamine plays in many aspects of tissue metabolism. Rather than focusing on the detailed metabolic fate of glutamine the present short review will consider the reasons why increased glutamine is utilised in the critically-ill, whether a conditional endogenous deficiency arises and finally whether correcting this deficiency affects outcome and ultimately survival. The present article is based on the hypothesis that a supply deficiency occurs, rather than suggesting that there is something metabolically extraordinary about glutamine in the absence of a relative deficiency.

Glutamine is the most abundant free amino acid, comprising about $25 \%$ of the plasma amino acids and $60 \%$ of the muscle free amino acids. Key to appreciating its nutritional importance in whole-body metabolism is that glutamine is synthesised by the cytosolic glutamine synthetase in many tissues, but degraded by mitochondrial glutaminase and utilised in high amounts by other tissues that do not synthesise it. Glutamine appears critical for the integrity and function of metabolically-active tissues. The cells of the immune system show wide functional regulation within the physiological range of plasma glutamine levels experienced in health and disease (Newsholme \& Calder, 1997). Both animal and ex vivo studies on lymphocytes demonstrate a striking dose-response relationship at physiological plasma glutamine concentrations which is critical for T lymphocyte function (Yaqoob \& Calder, 1997) and can be related to the clinical immunological response (Wilmore \& Shabert, 1998). Its very abundance, with large inter-organ fluxes combined with a diverse participation in transamination reactions, means that glutamine, which is a $\mathrm{C}_{5}$ chain with two $\mathrm{N}$ atoms, is a major inter-organ donor of $\mathrm{C}$ and $\mathrm{N}$. In terms of integrated whole-body biochemistry glutamine might be considered as an inter-organ and intercellular transporter of $\mathrm{C}$ and $\mathrm{N}$, and tool to target delivery of glutamine and glutamate to particular tissues as demand dictates (Fig. 1).

Glutamine regulates purine, pyrimidine and nucleotide synthesis, is a significant contributor to gluconeogenesis and is a precursor for glucosamine, glutathione and arginine synthesis. It has a role in acid-base balance in the kidney and, most importantly, has a central position in $\mathrm{N}$ homeostasis by the liver. The ability of the liver to consume or release glutamine, along with opposite fluxes of glutamine and alanine in the splanchnic bed, has recently been suggested as evidence for an efficient $\mathrm{N}$-sparing mechanism (Lopez et al. 1998). Both the lung and the brain produce glutamine, but it is skeletal muscle, by virtue of its size, that is the most important glutamine store, which together with its ability to synthesise glutamine de novo makes it the most important source of glutamine for the bloodstream. One of the initial responses to trauma or surgical stress, and in particular corticosteroids, is to export glutamine to the splanchnic bed and immune system from the free amino acid pool in muscle. This action leads to protein breakdown and de novo synthesis of glutamine from the released amino acids. Using improved analytical methods for the muscle protein-bound glutamine content the contribution from 


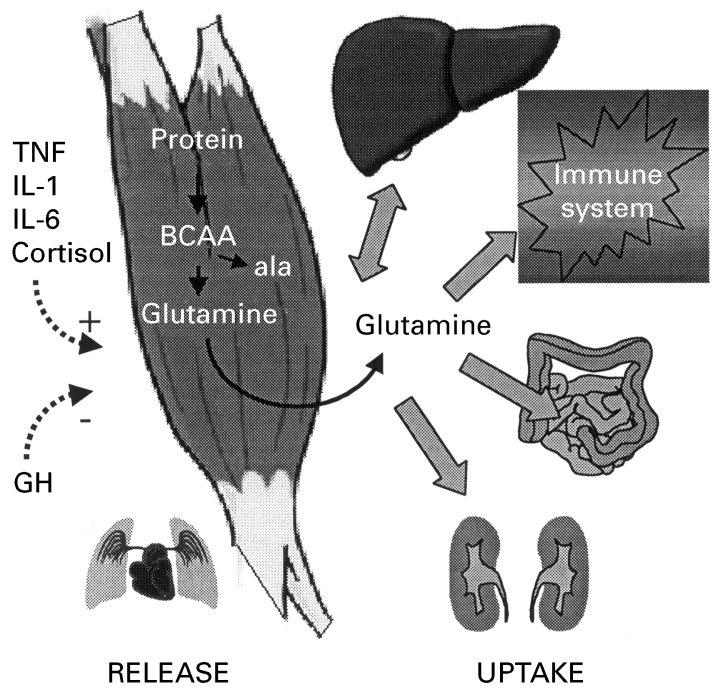

\author{
Cell protection \\ Glutathione, heat shock \\ proteins \\ Cell synthesis and repair \\ Immune cell function \\ Secretion and division \\ Enterocyte function \\ Citrulline, arginine synthesis \\ Liver synthesis \\ Urea, glucose, glutathione \\ Renal metabolsim \\ Acid-base, $\mathrm{NH}_{3}$ metabolism \\ Gluconeogenesis
}

Fig. 1. The stress-induced flux of glutamine from skeletal muscle to the liver, kidney, intestines and immune system, with indications of the different fates in various tissues. TNF, tumour necrosis factor; IL, interleukin; $\mathrm{GH}$, growth hormone; BCAA, branched-chain amino acids; ala, alanine.

protein breakdown or de novo synthesis has been reappraised. It had been thought that de novo synthesis contributed $60 \%$ of the turnover rate, but it is now recognised that this contribution may be as much as $85 \%$ (Kuhn et al. 1998). The inflammatory cytokine tumour necrosis factor $\alpha$ induces a 3-4-fold increase in glutamine synthetase activity in skeletal muscle through transcriptional regulation (Chakrabarti, 1998). Similarly, endotoxin has been shown to increase glutamine synthetase mRNA in both lung and muscle, but in animals with cachectic muscle the increases in glutamine synthetase protein levels are seen predominantly in lung tissue, signifying its importance when muscle mass is diminished (Elgadi et al. 1998).

\section{Evidence for a deficient supply of glutamine?}

That glutamine in most situations is readily synthesised classifies it as a dietary non-essential amino acid; however, during situations of extreme stress, particularly of prolonged duration, endogenous supply cannot match increased demand, and a conditional deficiency develops. The major fate of enteral dietary glutamine is to be extracted in the first pass by the gut and liver (Haisch et al. 2000). On the intestinal lumen interface glutamate can also be transported in large amounts and used in the oxidative processes or synthesis of proline, citrulline, arginine and glutathione (Reeds et al. 2000). However, elsewhere in the body on the arterial interface it is glutamine rather than glutamate that is the major transported substrate across cell membranes. This factor may be the key to the importance of the systemic plasma levels and (parenteral) delivery of glutamine for many tissues. Not only do we synthesise glutamine in many tissues, we also hold it free in solution in skeletal muscle at a gradient of 32:1 over plasma levels by active transport mechanisms. The classic observation by Vinnars et al. (1975) 25 years ago was that following surgery, trauma or sepsis the free glutamine pool is depleted. Despite the rapid fall in the intramuscular concentration of free glutamine, transport out of muscle is maintained and clearance from the plasma by other tissues increased, indicating activated transport mechanisms (Mittendorfer et al. 1999). In addition, disturbances in the $\mathrm{Na}$ electrochemical gradient seen in major injury and sepsis may lead to an inability to maintain the concentration gradient for glutamine across the muscle cell membrane (Hundal et al. 1987). Depending on the demands, there is increased utilisation by the gut, liver, spleen, kidney and immune cells. The process of muscle glutamine release is not fully understood, but it is intimately related to the stress response, particularly cortisol. Recent evidence suggests that just like post-operative insulin resistance, it can be attenuated post-operatively by immediate food intake (Soop et al. 2000). Stable-isotope studies of glutamine metabolism in critically-ill patients appear to support the extensive and robust large-animal studies that show net flux of glutamine from skeletal muscle to vital organs. Jackson et al. (1999) demonstrated in newly-admitted intensive care unit (ICU) patients a similar production rate but increased metabolic clearance rate from plasma, consistent with increased utilisation by other tissues, and only modest correction of low plasma levels with infusions of $28 \mathrm{~g}$ glutamine/d (Jackson et al. 2000).

\section{Is the availability of intracellular glutamate limiting?}

Later on during an intensive care stay, for instance with a severe sustained injury such as in burns, the efflux of glutamine cannot be maintained and plasma delivery declines. In children with burns the plasma levels of glutamine were reduced, whole-body flux of glutamine was $40 \%$ greater, but the turnover in the skeletal tissues was reduced, maintaining the net efflux approximately normal (Gore \& Jahoor, 2000). This observation implies a decrease in muscle glutamine production, which has been confirmed 


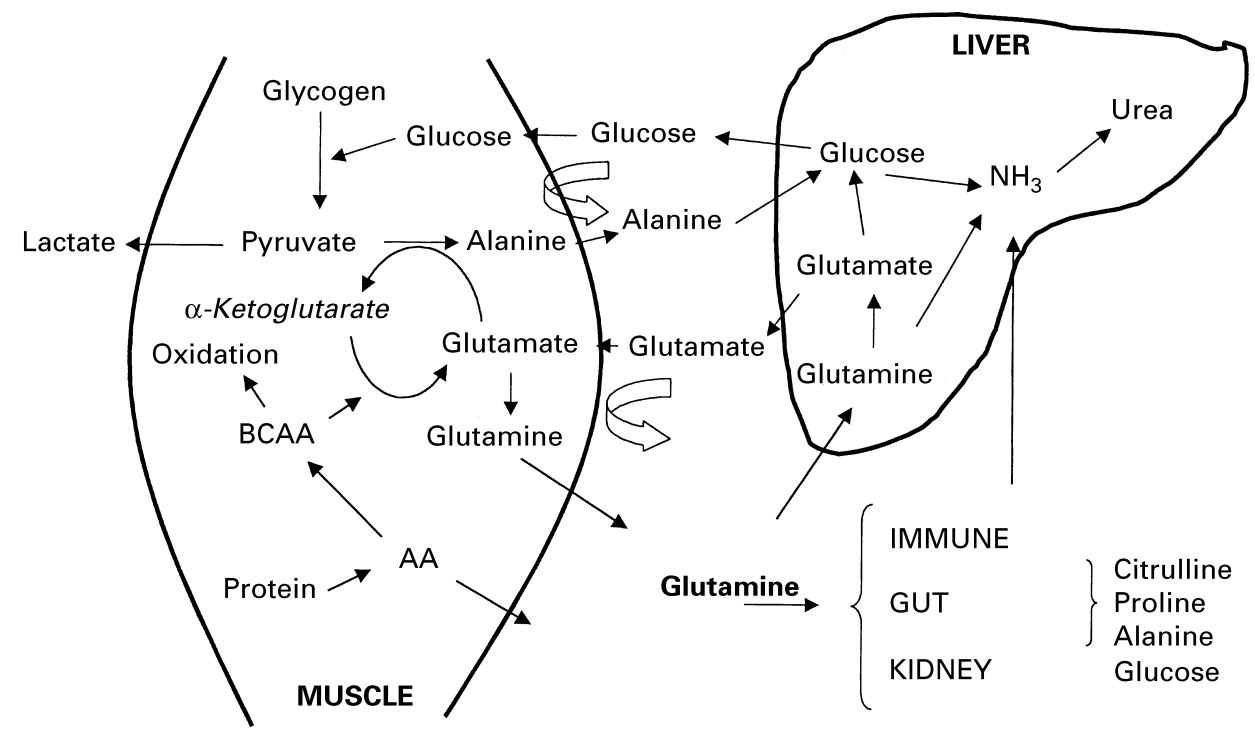

Fig. 2. Interrelationship of glutamine with glucose and alanine in skeletal muscle with the glucosealanine and glutamate-glutamine cycles with the liver. BCAA, branched-chain amino acids; AA, amino acids.

by Biolo et al. (2000) in a large study of twenty severelyburned patients 2 weeks into their critical illness. Arteriovenous balance studies across the muscle tissue showed an increased glucose influx, and increased alanine efflux without a rise in glutamine efflux, despite an accelerated muscle loss $(+150 \%)$. The intramuscular free glutamine pool was depleted $(-63 \%)$. It is hypothesised that the glucose consumption in burn injury results in increased requirement for non-oxidative pyruvate removal that can only occur either via lactate or transamination with glutamate to form alanine. This situation presents a problem for the skeletal muscle tissue in prolonged burn injury. Speculating on the current evidence suggests that the muscle has depleted its free glutamine pool and is exporting as much glutamine as it can synthesise to fuel demands from other organs. However, it also has an internal glutamate supply problem, which instead of being available for synthesis of glutamine, is being transaminated to $\alpha$ ketoglutarate in the production of alanine (see Fig. 2). Indirectly, other preliminary results show that high-dose parenteral glutamine therapy can lower intramuscular lactate in critically-ill patients, and would support the concept that glutamate supply for pyruvate clearance may be limited (Tjäder et al. 2000).

\section{Glutamine and cellular protective mechanisms}

Another major demand on the glutamate supply in ICU patients is for the production of the major cellular antioxidant glutathione (Wernerman et al. 1999). Low intramuscular glutathione levels are correlated with low glutamine and glutamate levels in the critically-ill, but surprisingly the cysteine and glycine levels are maintained (Hammarqvist et al. 1997). An explanation may be that in the presence of protein breakdown there is plenty of substrate available, except when alternative demands for glutamate predominate, leading to limitation of glutathione production. Mice fed supplemented enteral diets and then challenged with endotoxin showed maintenance of glutathione levels, with increased numbers of T-cells, and glutamine prevented the apoptosis of B-cells in the Peyer's patches while arginine, glycine or $n-3$ fatty acids did not (Manhart et al. 2000). In pro-monocytic cell cultures glutamine in the medium protected against heat-induced apoptosis by enhancing the expression of heat-shock proteins (Weingartmann et al. 1998). Glutamine has been shown to be protective to intestinal cells through heat-shock protein 70 generation (Wischmeyer et al. 1997). The same workers have presented preliminary findings (Wischmeyer et al. 2000) that suggest that acute glutamine infusion in endotoxin models shows striking protection against tissue damage, probably mediated via heat-shock protein expression and glutathione.

\section{Glutamine, immune function and infective morbidity in the critically-ill}

In the critically-ill ICU patient acquired infections are common. Along with intravascular catheters, the presence of a nasogastric tube and endotracheal tube alter bacterial and fungal colonisation, while disturbances in enteral nutrition and gastrointestinal function alter the microflora. Most infections in the ICU are acquired from flora abnormally colonising various mucus membranes or skin entry sites. The European Prevalence of Infection in Intensive Care Study (Vincent et al. 1995) showed the importance of infection in ICU patients, with approximately half acquiring infection on the ICU. There was a significant correlation between the mortality rate and the prevalence of intensive care-acquired infection. Patients with pneumonia (odds ratio $1.91 ; 95 \%$ CI $1 \cdot 6,2 \cdot 29$ ), laboratory-proven bloodstream infection (odds ratio 1.73; 95\% CI 1.25, 2.41) and clinical sepsis (odds ratio $3 \cdot 5 ; 95 \%$ CI $1 \cdot 71,7 \cdot 18$ ) had increased risk of death. Not surprisingly, multiple factors 
were associated with new infections, including mechanical ventilation, diagnosis of trauma, the use of invasive devices and the duration of ICU stay, but not length of hospital stay before ICU admission.

Along with the barrier protective mechanisms, the maintenance of an effective innate immune system response (phagocytosis and active monocytes) is essential for the initial prevention and control of the infection. However, the ultimate recognition and subsequent controlled resolution of infective inflammation requires an optimal function of the acquired (adaptive) immune system dependent on T- and Bcell control. The clinical sepsis response combines proinflammatory and counter-regulatory or anti-inflammatory signalling to ensure an optimal balance, which intimately effects the T-cell response. One probable target tissue most likely to become deficient of glutamine supply during trauma and sepsis is the immune system, where the demand for production of receptors or cytokines and rapid clonal expansion is increased (Calder \& Yaqoob, 1999). A concept of immune paralysis (or imbalance) is thought to occur which predisposes to repeated infections. Enteral and parenteral studies in small animals (Kew et al. 1999) suggest that glutamine increases the proportion of CD4+ lymphocytes in the spleen, and in stimulated macrophages enhances the production of tumour necrosis factor $\alpha$ and of interleukins $1 \beta$ and 6 (Wells et al. 1999). These features indicate a preferential enhancement of the T-helper lymphocyte response characterised by interleukin 2 and interferon $\gamma$ production (Lin et al. 2000), with macrophage activation and improved cell-mediated immunity towards bacteria, fungi, viruses and tumour cells. The improved lymphocyte function seen following glutamine appears to be closely related to improvements in cellular glutathione status (Chang et al. 1999). Where a host immune system is impaired, e.g. due to depletion of glutamine, the body may be less able to mount an effective response to infection. This factor could explain why colonisation with candida in the severely-ill long-stay ICU patient is common (Vincent et al. 1995) and leads to an increased risk of ICU-acquired infection with candida (Pittet et al. 1994), which is associated with a very high mortality (Wenzel, 1995).

Glutamine parenteral nutrition improves survival in rats with abdominal sepsis (Ardawi, 1991). Glutamine is protective against apoptosis in immune (Petronini et al. 1996) and endothelial (Parolari et al. 1997) cell lines which is induced by sepsis (Kotchkiss et al. 1997), and enhances the protective expression of heat-shock proteins (Weingartmann et al. 1998). Since dietary glutamine is utilised primarily by the enterocytes and gut-associated lymphoid tissue (GALT; Matthews et al. 1993), the high glutamine requirement of immune cells outside the gastrointestinal tract must be met from the systemic circulation and influenced by circulating levels. The migration of lymphocytes through the GALT means that secretory immunoglobulin A function at all mucosal sites is influenced by GALT activity. In the absence of enteral feeding in mice, parenteral glutamine improves the primary immune defences against infections of all mucosal surfaces including respiratory (Li et al. 1998), probably by optimising lymphocyte function in the GALT and the production of secretory immunoglobulin A. In a rat model prolonged total parenteral nutrition with glutamine not only maintained mucosal morphology and reduced bacterial translocation, but also completely abolished line infections (McAndrew et al. 1998). ICU trauma patients given enteral glutamine showed a potentially beneficial rise in CD4:CD8 T-cells (Jensen et al. 1996). Enteral glutamine in very-low-birth-weight neonates more than halved the incidence of hospital-acquired sepsis (Neu et al. 1997) and improved markers of T-cell function. Delivery of $30 \mathrm{~g}$ glutamine/d jejunally in multiple-trauma patients led to a significant reduction in pneumonia $(P<0.02)$, bacteraemia $(P<0.05)$ and severe sepsis $(P<0.02)$ (Houdijk et al. 1998). Glutamine total parenteral nutrition in allogenic bone marrow-transplant patients resulted in fewer clinical infections (Ziegler et al. 1992) and a greater number of total lymphocytes, and CD4+ lymphocytes (but not B lymphocytes or natural killer cells; Ziegler et al. 1998). Following colo-rectal surgery glutamine total parenteral nutrition restored T-cell DNA synthesis (O'Riordain et al. 1994), and in severe acute pancreatitis reduced mononuclear cell interleukin 8 release (De Beaux et al. 1998). Total parenteral nutrition with glutamine following bowel surgery improved recovery of lymphocyte counts, and a greater generation of cysteinyl-leukotrienes from polymorphonuclear neutrophil granulocytes indicative of improved immune function (Morlion et al. 1998). Glutathione is a necessary cofactor in the production of leukotriene $\mathrm{C}_{4}$ and, interestingly, work published by the same authors (Morlion et al. 2000) suggests that non-surviving criticallyill patients, compared with those that survived, show an inability to generate leukotriene C4. Parenteral glutamine therapy in man has recently been shown to prevent the down regulation of monocyte function, as expressed by human leucocyte-associated antigen-DR expression, following major abdominal surgery (Spittler et al. 2000).

\section{The evidence for benefit from exogenous glutamine replacement}

Recent reviews provide extensive past evidence (Griffiths, 1999; Wernerman \& Hammarqvist, 1999). Following major surgery there have been five studies which have given parenteral glutamine (two of which were multicentre studies) and have shown significantly improved clinical outcomes, in particular shorter hospital stays (no. of patients; 28, Morlion et al. 1998; 121, Fürst, 1999; 120, Jiang et al. 1999; 30, Karwowska et al. 2000; 33 Di Cosmo et al. 2000). In the critically-ill ICU patient, if a conditional deficiency occurs and glutamine supply becomes limiting, the benefit of its exogenous replacement would be expected to be seen as a reduction in the number of deaths later during the ICU stay. Deaths early on are due to the magnitude of the initial insult, and usually involve a failure of a single organ system. The patient who survives this initial period is exposed to acquired intensive care infection, and if recovery does not follow, death occurs as the result of progressive multiple organ failure. This situation means that the mortality risks of the initial illness are overtaken by the risks of a sustained ICU stay. Griffiths et al. (1997) examined this hypothesis using a prospective block-randomised double-blind design testing whether 'all in one' glutamine parenteral nutrition compared with an 
isonitrogenous isoenergetic control would influence outcome, with the end points of morbidity, mortality and cost at 6 months post intervention. Wilmore (1997) and Wernerman (1998) have discussed this paper. The study examined a very-high-risk group of eighty-four patients with multiple organ failure and gut failure dependent only on parenteral nutrition. A robust end point of survival at 6 months was chosen in order to include all long-stay ICU patients and be consistent with time scale of death from multiple organ failure secondary to repeated insults and infections. Plasma glutamine was reduced similarly in both groups, from a normal value of $0.64(95 \%$ CI $0.55,0.72)$ $\mathrm{mmol} / \mathrm{l}$ to a mean of $0.34(95 \%$ CI $0 \cdot 26,0 \cdot 43) \mathrm{mmol} / \mathrm{l}$. In a representative sample of these patients muscle glutamine was depleted by $\geq 75 \%$, to a mean of $3 \cdot 1(95 \%$ CI $2 \cdot 2,4 \cdot 0)$ $\mathrm{mmol} / \mathrm{kg}$ wet weight. Over three-quarters of the patients had major sepsis, with intra-abdominal causes the most common. Survival measured at 6 months was significantly better with glutamine $(57 \%)$ compared with the control $(33 \% ; P=0.049)$. The mortality in the control group was similar to that of an age- and illness-severity-matched group receiving a conventional feed in the year preceding the study. Differences in mortality increased with time on parenteral nutrition, and were only related to the presence or absence of glutamine and not related to age, illness severity or total amount of nutrition received. Despite the greater survival in the glutamine group total hospital costs did not increase, as might be expected since the excess deaths in the control group occurred later and had a significantly longer (and therefore costlier) post-intervention stay $(P=0.013)$ and use of the ICU. As a consequence, using a regimen containing glutamine led to a $50 \%$ reduction in the total ICU and hospital cost when expressed per survivor. A low BMI is an independent predictor of excess mortality in multiple organ failure, and this factor becomes evident at about $25 \mathrm{~d}$ into the illness (Galanos et al. 1997). Multiple organ failure was the principal cause of death in the ICU and, strikingly, the excess death in the control group occurred after $21 \mathrm{~d}$ in the ICU, consistent with the time scales expected with muscle wasting; the majority of these deaths were a result of multiple organ failure. Subsequent analysis to explore the relationship between infection and outcome showed in those patients fed for more than $5 \mathrm{~d}$ that there were progressively more and repeated acquired intensive care infections in the control patients, yet they encountered the same risk with a similar duration of parenteral nutrition and stay on the ICU. In those patients fed for $\geq 5 \mathrm{~d}$ the significant excess mortality was still present in control patients (eighteen of twenty-seven compared with nine of twenty-five receiving glutamine; $P=0.05$ ), of whom most died within the ICU from multiple organ failure (sixteen of twenty-seven controls compared with eight of twenty-five receiving glutamine). Consistent with a possible cell-mediated impaired $\mathrm{T}$ lymphocyte function, control patients not given glutamine had more fungal infections and higher mortality. Despite a similar colonisation rate with candida, duration of parenteral nutrition and ICU stay, patients receiving glutamine developed only four candida infections with no deaths, while nine control patients developed candida infections, of whom six died from multiple organ failure (Griffiths et al. 2000).

\section{Which patients and how much?}

It may be that our sickest and oldest patients (who have less muscle) should start glutamine as soon as possible. Although enteral glutamine and/or any of its precursors will supply the gut and GALT in less-ill patients, parenteral supplements may be needed in the sicker patients to achieve adequate systemic delivery. Of course, glutamine was only omitted from standard amino acid solutions in the 1960s because of its poor solubility and instability with heat sterilisation. There is no logical reason for omitting glutamine now that dipeptides of glutamine have overcome these problems and practical parenteral formulations are available. How much should be given remains open to debate, but an in-depth discussion of glutamine dose has been made by Griffiths \& Andrews (2000). Most studies have used fixed proportions, delivering from between 15 and $30 \mathrm{~g} / \mathrm{d}$. A post-operative patient with lower glutamine demands may require an amount at the lower end of the range, while a severely-injured patient with multiple trauma or burns may require $25-35 \mathrm{~g} / \mathrm{d}$. Whether the ability to raise plasma glutamine is a sufficient indicator of appropriate dose is not clear, but the proposed benefits to the immune system would suggest that this approach is reasonable. There is a lack of clinical evidence showing enteral supplements can significantly raise plasma or tissue glutamine levels for a sustained period. Indeed, there is contrary evidence that suggests plasma glutamine levels are slower to recover with the same dose of glutamine given by the enteral route compared with the parenteral route (Fish et al. 1997). The enteral route may be sufficient when given early to the non-infected patient (e.g. following trauma) to improve GALT function and the immune defence against infection (Houdijk et al. 1998), but adequately delivery is a challenge. However, for the already severely-stressed or infected ICU patient enteral supplements alone may be inadequate, and parallel parenteral support is likely to be required.

It is of course early days in the use of glutamine in intensive care, and many practitioners remain reluctant to accept the evidence that a deficiency can arise and that its correction can influence ICU survival. This reluctance is understandable, given the failure of the many studies in sepsis to affect outcome. Multicentre studies in intensive care would be preferable to confirm the evidence, and at least one study, in France, is due to be completed shortly. However, these studies require considerable cost and investment, with recruitment from a limited pool of patients who are already involved in other research studies where the therapy under test is either more costly or carries a potential greater risk of harm that must be defined. Although further studies are appearing in the literature, weaknesses in their design may preclude benefits from being detected, as for example in the study by Powell-Tuck et al. (1999). In this study there was a lack of patient homogeneity, and the more severely-ill patients at higher risk of deficiency were not studied.

\section{Conclusion}

Historical parallel reminds us that deficiency of a single nutrient impairs physiological function, is life threatening 
and can also take time to be generally accepted. Scurvy, the scourge of the British navy for centuries, would appear in sailors after about 6 months at sea, was physically debilitating and accounted for the majority of deaths occurring at sea. Lord Anson's expedition around the globe (1740-4) resulted in 1317 deaths from the five-ship complement of 1955 sailors, $75 \%$ of the deaths being directly attributed to scurvy. Despite the use of citrus fruits by our Dutch neighbours, the cure was not proved until a Scottish naval surgeon, Dr James Lind (1716-91), undertook probably the first controlled clinical therapeutic trial on board HMS Salisbury in 1754 (see Porter, 1997). He randomised twelve sailors with advanced scurvy lying in his sickbay and in pairs gave them different acidic concoctions. Only those who received citrus fruits were back on duty within $6 \mathrm{~d}$. However, it took the British Navy another 40 years before it accepted Dr Lind's recommendations. This situation may have occurred because James Cook (1728-1779) and his commanders could not accept such a simple option, and believed a more complex nutritional and physical management was required. From 1795 Nelson's navy had the advantage of lemon juice, which may well have contributed to his success in 1805 at the battle of Trafalgar. Sadly, soon after this battle the Navy introduced a costcutting option and decided to use limejuice instead, which was obtained cheaply from the West Indies. This change resulted in British sailors being given the nickname 'Limeys' by the US sailors during the maritime battles of 1812. Unfortunately, limejuice contained only one-third the vitamin $\mathrm{C}$ of other citrus fruits, and scurvy reoccurred on long voyages throughout the rest of that century.

If this parallel should hold true for glutamine, based on the evidence currently available, we may fail to show improvement if we only give glutamine by the enteral route or give insufficient amounts to our sickest patients.

\section{Acknowledgements}

Great thanks are given to Mrs C. Jones and colleagues on the Intensive Care Unit, Whiston Hospital. R.D.G. and the University of Liverpool have received grant support for clinical research work on glutamine from The Jules Thorn Charitable Trust, Mersey Regional Research Fund, The Wellcome Trust, Oxford Nutrition UK and Fresenius-Kabi (previously Pharmacia \& Upjohn).

\section{References}

Ardawi MS (1991) Effect of glutamine-enriched total parenteral nutrition on septic rats. Clinical Science 81, 215-222.

Biolo G, Fleming RYD, Maggi SP, Nguyen TT, Herndon DN \& Wolfe RR (2000) Inhibition of muscle glutamine formation in hypercatabolic patients. Clinical Science 99, 189-194.

Calder PC \& Yaqoob P (1999) Glutamine and the immune system. Amino Acids 17, 227-241.

Chakrabarti R (1998) Transcriptional regulation of the rat glutamine synthetase gene by tumor necrosis factor-alpha. European Journal of Biochemistry 254, 70-74.

Chang WK, Yang KD \& Shaio MF (1999) Lymphocyte proliferation modulated by glutamine: involved in the endogenous redox reaction. Clinical and Experimental Immunology 117, $482-488$.
De Beaux AC, O'Riordan MG, Ross JA, Jodozi L, Carter DC \& Fearon KCH (1998) Glutamine-supplemented total parenteral nutrition reduces blood mononuclear cell interleukin-8 release in severe acute pancreatitis. Nutrition 14, 261-265.

Di Cosmo L, Neri A, Piccolomini A, Vuolo G, Guarnieri A, Mariani F, Testa M, Paolini B \& Mattei R (2000) Glutamine supplemented TPN in major abdominal surgery. Clinical Nutrition 19, 23 Abstr.

Elgadi KM, Labow BI, Abcouwer SF \& Souba WW (1998) Sepsis increases lung glutamine synthetase expression in the tumorbearing host. Journal of Surgical Research 78, 18-22.

Fish J, Sporay G, Beyer K, Jones J, Kihara T, Kennedy A, Apovian C \& Jensen GL (1997) A prospective randomized study of glutamine-enriched parenteral compared with enteral feeding in postoperative patients. American Journal of Clinical Nutrition 65, 977-983.

Fürst P (1999) Effects of supplemental parenteral L-alanyl-Lglutamine (ALA-GLN) following elective operations: A European multicenter study. Clinical Nutrition 18, 16 Abstr.

Galanos AN, Pieper CF, Kussin PS, Winchell MT, Fulkerson WJ, Harrell FE, Teno JM, Layde P, Connors AF, Phillips RS \& Wenger NS, for the SUPPORT Investigators (1997) Relationship of body mass index to subsequent mortality among seriously ill hospitalised patients. Critical Care Medicine 25, 1962-1968.

Gore DC \& Jahoor F (2000) Deficiency in peripheral glutamine production in paediatric patients with burns. Journal of Burn Care and Rehabilitation 21, 172-177.

Griffiths RD (1999) Glutamine: establishing clinical indications. Current Opinion in Clinical Nutrition and Metabolic Care 2, 177-182.

Griffiths RD, Allen KD \& Jones C (2000) Glutamine TPN and intensive care acquired infections. Clinical Nutrition 19, 42 Abstr.

Griffiths RD \& Andrews F (2000) Effects of route and dose of immunonutrition compounds. In Update in Intensive Care and Emergency Medicine. vol. 34, From Nutritional Support to Pharmacologic Nutrition in the ICU, pp. 409-424 [K Kudsk and C Pichard, editors]. Berlin: Springer-Verlag.

Griffiths RD, Jones C \& Palmer TEA (1997) Six-month outcome of critically ill patients given glutamine supplemented parenteral nutrition. Nutrition 13, 295-302.

Haisch M, Fukagawa NK \& Matthews DE (2000) Oxidation of glutamine by the splanchnic bed in humans. American Journal of Physiology 278, E593-E602.

Hammarqvist F, Luo J-L, Cotgreave IA, Andersson K \& Wernerman J (1997) Skeletal muscle glutathione is depleted in critically ill patients. Critical Care Medicine 25, 78-84.

Houdijk APJ, Rijnsburger ER, Jansen J, Wesdorp RIC, Weis JK, McCamish MA, Teerlink T, Meuwissen SG, Haarman HJ, Thijs LG \& van Leeuwen PA (1998) Randomised trial of glutamineenriched enteral nutrition on infectious morbidity in patients with multiple trauma. Lancet 352, 772-776.

Hundal HS, Rennie MJ \& Watt PW (1987) Characteristics of Lglutamine transport in perfused rat muscle. Journal of Physiology 393, 283-305.

Jackson NC, Carroll PV, Russell-Jones DL, Sönksen PH, Treacher DF \& Umpleby AM (1999) The metabolic consequences of critical illness: acute effects on glutamine and protein metabolism. American Journal of Physiology 276, E163-E170.

Jackson NC, Carroll PV, Russell-Jones DL, Sönksen PH, Treacher DF \& Umpleby AM (2000) Effects of glutamine supplementation, GH, and IGF-1 on glutamine metabolism in critically ill patients. American Journal of Physiology 278, E226-E233.

Jensen GL, Miller RH, Talabiska DG, Fish J \& Gianferante L (1996) A double-blind, prospective, randomized study of glutamine-enriched compared with standard peptide-based 
feeding in critically ill patients. American Journal of Clinical Nutrition 64, 615-621.

Jiang ZM, Cao JD, Zhu XG, Zhaos WX, Yu JC, Ma EL, Wang XR, Zhu MW, Shu H \& Liu YW (1999) The impact of alanylglutamine on clinical safety, nitrogen balance, intestinal permeability, and clinical outcome in postoperative patients: a randomized, double-blind, controlled study of 120 patients. Journal of Parenteral and Enteral Nutrition 23, S62-S66.

Karwowska KA, Szulc R, Dworacki G \& Keromski J (2000) Influence of glutamine enriched parenteral nutrition on nitrogen balance and immunological status in patients undergoing elective aortic aneurysms repair. Clinical Nutrition 19, 22 Abstr.

Kew S, Wells SM, Yaqoob P, Wallace FA, Miles EA \& Calder PC (1999) Dietary glutamine enhances murine T-lymphocyte responsiveness. Journal of Nutrition 129, 1524-1531.

Kotchkiss RS, Swanson PE, Cobb JP, Jacobson A, Buchman TG \& Karl IE (1997) Apoptosis in lymphoid and parenchymal cells during sepsis: findings in normal and $\mathrm{T}$ - and B-cell-deficient mice. Critical Care Medicine 25, 1298-1307.

Krebs HA (1935) The synthesis of glutamine from glutamic acid and ammonia and the enzymatic hydrolysis of glutamine in animal tissues. Biochemical Journal 29, 1951.

Kuhn KS, Schuhman K, Stehle P \& Fürst P (1998) De novo synthesis represents a greater proportion of muscle glutamine turnover than previously assumed. Clinical Nutrition 17, Suppl. 1, 10-O.33 Abstr.

Li J, King BK, Janu PG, Renegar KB \& Kudsk KA (1998) GlycylL-glutamine-enriched total parenteral nutrition maintains small intestine gut-associated lymphoid tissue and upper respiratory tract immunity. Journal of Parenteral and Enteral Nutrition 22, 31-36.

Lin MT, Saito H, Chang KJ \& Chen WJ (2000) Glutamine enriched parenteral nutrition improves splenocyte interferon-gamma production. Nutrition Research 20, 805-813.

Lopez HW, Moundras C, Morand C, Demigne C \& Remesy C (1998) Opposite fluxes of glutamine and alanine in the splanchnic area are an efficient mechanism for nitrogen sparing in rats. Journal of Nutrition 128, 1487-1494.

McAndrew HF, Lloyd DA, Rintala R \& van Saene HK (1998) Intravenous glutamine or short chain fatty acids reduce central venous catheter infection in a total parenteral nutrition model. Journal of Pediatric Surgery 34, 281-285.

Manhart N, Vierlinger K, Akomeah R, Bergmeister H, Spittler A \& Roth E (2000) Influence of enteral diets supplemented with key nutrients on lymphocyte subpopulations in Peyer's patches of endotoxin-boostered mice. Clinical Nutrition 19, 265-269.

Matthews DE, Marano MA \& Campbell RG (1993) Splanchnic bed utilisation of glutamine and glutamic acid in humans. American Journal of Physiology 264, E848-E854.

Mittendorfer B, Gore DC, Herndon DN \& Wolfe RR (1999) Accelerated glutamine synthesis in critically ill patients cannot maintain normal intracellular free glutamine concentrations. Journal of Parenteral and Enteral Nutrition 23, 243-250.

Morlion BJ, Stehle P, Wachter P, Siedhoff HP, Koller M, Konig W, Fürst P \& Puchstein C (1998) Total parenteral nutrition with glutamine dipeptide after major abdominal surgery - a randomized, double-blind, controlled study. Annals of Surgery 227, 302-308.

Morlion BJ, Torwesten E, Kuhn KS, Puchstein C \& Fürst P (2000) Cysteinyl-leukotriene generation as a biomarker for survival in the critically ill. Critical Care Medicine 28, 3655-3658.

Neu J, Roig JC, Meetze WH, Veerman M, Carter C, Millsaps M, Bowling D, Dallas MJ, Sleasman J, Knight T \& Auestad N (1997) Enteral glutamine supplementation for very low birth weight infants decreases morbidity. Journal of Pediatrics 131, 691-699.
Newsholme EA \& Calder PC (1997) The proposed role of glutamine in some cells of the immune system and speculative consequences for the whole animal. Nutrition 13, 728-730.

O'Riordain MG, Fearon KC, Ross JA, Rogers P, Falconer JS, Bartolo DCC, Garden OJ \& Carter DC (1994) Glutaminesupplemented total parenteral nutrition enhances T-lymphocyte response in surgical patients undergoing colorectal surgery. Annals of Surgery 220, 212-221.

Parolari A, Sala R, Antona C, Bussolatti O, Alamanni F, Mezzadri P, Dall'Asta V, Gazzola GC \& Biglioli P (1997) Hypertonicity induces injury to cultured human endothelium: attenuation by glutamine. Annals of Thoracic Surgery 64, 1770-1775.

Petronini PG, Urbani S, Alfieri R, Borghetti AF \& Guidotti GG (1996) Cell susceptibility to apoptosis by glutamine deprivation and rescue: survival and apoptotic death in cultured lymphomaleukemia cell line. Journal of Cell Physiology 169, 175-185.

Pittet D, Monod M, Suter P, Frenk E \& Auckenthaler R (1994) Candida colonisation and subsequent infections in the critically ill surgical patients. Annals of Surgery 220, 751-758.

Porter R (1997)The Greatest Benefit to Mankind: A Medical History of Humanity from Antiquity to the Present. London: HarperCollins.

Powell-Tuck J, Jamieson CP, Bettany GEA, Obeid O, Fawcett HV, Archer C \& Murphy DL (1999) A double blind, randomised, controlled trial of glutamine supplementation in parenteral nutrition. Gut 45, 82-88.

Reeds PJ, Burrin DG, Stoll B \& Jahoor F (2000) Intestinal glutamate metabolism. Journal of Nutrition 130, Suppl. 4, 978S-982S.

Soop MM, Nygren J, Thorell A, Hammarqvist F \& Ljungqvist O (2000) Muscle glutamine depletion after major orthopaedic surgery can be attenuated by immediate postoperative spontaneous food intake. Clinical Nutrition 19, 37 Abstr.

Spittler A, Sautner T, Gomiciewicz A, Oehler R, Manhart N, Függer R \& Roth E (2000) Postoperative glutamine-dipeptide infusion prevents the decrease of HLA-DR expression on monocytes induced by surgery. Clinical Nutrition 19, 22 Abstr.

Tjäder IE, Essén P, Hultman E, Forsberg A \& Wernerman J (2000) Glutamine supplementation to ICU patients affects lactate metabolism in skeletal muscle. Clinical Nutrition 19, 46 Abstr.

Vincent J-L, Bihari DJ, Suter PM, Bruining HA, White J, NicholasChanion MH, Wolff M, Spencer RC, Hemmer M \& EPIC International Advisory Committee (1995) The prevalence of nosocomial infection in Intensive Care Units in Europe. Results of the European Prevalence of Infection in Intensive Care (EPIC) Study. Journal of the American Medical Association 274, 639-644.

Vinnars E, Bergström J \& Fürst P (1975) Influence of the postoperative state on the intracellular free amino acids in human muscle tissue. Annals of Surgery 182, 665-671.

Weingartmann G, Brabec M, Oehler R, Spittler A \& Roth E (1998) Glutamine protects U937 cells against heat induced apoptosis in association with high expression of hsp70. Clinical Nutrition 17, 34-P.18

Wells SM, Kew S, Yaqoob P, Wallace FA \& Calder PC (1999) Dietary glutamine enhances cytokine production by murine macrophages. Nutrition 15, 881-884.

Wenzel RP (1995) Nosocomial candidemia: risk factors and attributable mortality. Clinical Infectious Disease 20, $1531-1534$.

Wernerman J (1998) Glutamine-containing TPN: a question of life and death for intensive care unit-patients? Clinical Nutrition 17, 3-6.

Wernerman J \& Hammarqvist F (1999) Glutamine: a necessary nutrient for the intensive care patient. International Journal of Colorectal Disease 14, 137-142. 
Wernerman J, Luo J-L \& Hammarqvist F (1999) Glutathione status in critically-ill patients: possibility of modulation by antioxidants. Proceedings of the Nutrition Society 58, 677-680.

Wilmore DW (1997) Glutamine saves lives! What does it mean? Nutrition 13, 375-376.

Wilmore DW \& Shabert JK (1998) Role of glutamine in immunologic responses. Nutrition 14, 618-626.

Wischmeyer PE, Musch M, Kahana M, Chang E \& Roizen M (2000) Heat shock protein induction in heart and lung tissue after glutamine infusion. Anesthesia and Analgesia 90, S149.

Wischmeyer PE, Musch MW, Madonna MB, Thisted R \& Chang EB (1997) Glutamine protects intestinal epithelial cells: role of inducible HSP70. American Journal of Physiology 272, E879-E884.

Yaqoob P \& Calder PC (1997) Glutamine requirements of proliferating T Lymphocytes. Nutrition 13, 646-651.

Ziegler TR, Bye RL, Persinger RL, Young LS, Antin JH \& Wilmore DW (1998) Effects of glutamine supplementation on circulating lymphocytes after bone marrow transplantation: a pilot study. American Journal of Medical Science 315, 4-10.

Ziegler TR, Young LS, Benfell K, Scheltinga M, Hortos K, Bye R, Morrow FD, Jacobs DO, Smith RJ, Antin JH \& Wilmore DW (1992) Clinical and metabolic efficacy of glutaminesupplemented parenteral nutrition after bone marrow transplantation. Annals of Internal Medicine 116, 821-828. 